\title{
Industry Platforms as Facilitators of Disruptive IoT Innovations
}

\author{
Cristian Ionuţ Pîrvan ${ }^{1}$ Ozgur Dedehayir ${ }^{2 *}$, and Hans Le Fever ${ }^{1}$
}

Abstract: We undertake an inductive study of four firms developing industry platforms upon which potentially disruptive IoT products and services are developed by external firms. Our results indicate there to be four types of industry platform (generalist, specialist, technology-centric, and industry-centric), each facilitating a unique mode of disruptive change. We propose that technology-centric platforms are more likely to facilitate business model disruptions, while industry-centric platforms are more likely to facilitate technological disruptions. Generalist industry platforms, by contrast, are able to facilitate both business model and technological disruptions, given the freedom they allow IoT firms to build their product and service solutions.

Keywords: internet of things; IoT; disruptive innovations; digital platforms; industry platforms

Submitted: Aug 28 th 2019 / Approved: Oct ${ }^{\text {3rd }}, 2019$

\section{Introduction}

By the beginning of 2018, Netflix's market capitalization exceeded $\$ 100$ billion, Airbnb acquired a valuation of $\$ 30$ billion after another round of funding, while Spotify's market valuation reached $\$ 26$ billion following its initial public offering. What do these firms have in common? Netflix, Airbnb, and Spotify are not traditional players in their respective industries, but are disruptors, having reimagined the way they could better serve their markets to great effect. What is just as interesting and yet often unseen is that the platform businesses of these and other firms have been built on top of another platform, namely, the Amazon Web Services platform. Through this arrangement, arduous tasks such as database replication and scaling, as well as capacity provisioning, whether it is for storage, servers, or networks, have all been reduced through Amazon's platform to a basic API (Application Programming Interface) call, thus allowing the firms to devote resources only to their core businesses. The success of Netflix, Airbnb, and Spotify have thus come about through the facilitating partnership offered by Amazon. We identify these facilitating platforms, such as the Amazon Web Services, as 'industry platforms' (Gawer \& Cusumano, 2002; Cusumano, 2010; Gawer 2014), defined as "products, services, or technologies that act as a foundation upon which external innovators, organized as an innovative business ecosystem, can develop their own complementary products, technologies, or services" (Gawer \& Cusumano, 2013, p.417).

Platforms, at industry level, are steadily becoming the pervasive, dominant business model of the $21^{\text {st }}$ century (Hoelck \& Ballon, 2015). In the automotive sector, for instance, Audi Connect, BMW ConnectedDrive, and Mercedes Connect Me platforms are already used to boost industry-wide innovation (Mikusz et al., 2015). Scholars have captured these phenomena in studies that incorporate platform thinking, such as in evaluating incumbent performance with a focus on how established companies are able to keep their dominant positions in response to emerging disruptive innovations (Ansari \& Krop,
2012; Brown et al., 2007). Other studies have, in turn, centered on the successful strategies employed by firms to disrupt incumbents in different industries through platform-based business models (Kenagy \& Christensen, 2002; Sapsed et al., 2007; Soleimani \& Zenios, 2011; Walsh, 2004). Notwithstanding these earlier contributions, there is still little known about how industry platforms facilitate disruptive change (Christensen, 1997; Dedehayir et al., 2014; Shea, 2005).

This empirical and conceptual gap deserves attention given the technological paradigm shift currently taking place, accelerated by the Internet of Things (IoT) phenomenon, which is likely to impact many industries (Harris et al., 2015; Uckelmann et al., 2011). IoT captures the interaction and cooperation of objects - such as Radio-Frequency IDentification (RFID) tags, sensors, actuators, mobile phones, etc. - using unique addressing schemes and modern wireless telecommunication technology, to reach common goals (Atzori et al., 2010; Fleisch, 2010; Gubbi et al., 2013). It is currently one of the most attractive and impactful research areas for future work, especially when converged with other synergistic research streams such as Big Data (e.g. Wang et al., 2018). In July 2015, McKinsey \& Company concluded that the IoT's total economic impact could be as high as $\$ 3.9$ trillion to $\$ 11.1$ trillion per annum by the year 2025. In January 2016, Gartner argued that by the year 2020, more than half of the major new business processes and systems will include some elements of the IoT. Furthermore, a study conducted by the GSM Association, representing the interests of nearly 800 mobile operators worldwide, revealed that in the coming years, the rate of expansion and evolution of IoT will make it imperative for industry actors to cooperate on interoperability to avoid fragmentation and ensure that different devices and services will be able to communicate seamlessly (Bouverot, 2015). Given these trends and the innate, systemic nature of IoT, we anticipate that the number of platforms and platform-centric business ecosystems centering about IoT products and services will increase noticeably in the coming years. We additionally expect to see a greater abundance of IoTbased businesses that build upon industry platforms, which hold the potential of disrupting existing marketplaces (Ebersold \& Hartford, 2015).

1) Leiden Institute of Advanced Computer Science, Leiden University, Niels Bohrweg 1, 2333 CA, Leiden, The Netherlands

2) Queensland University of Technology, School of Management, Level 9, Z Block, 2 George Street, Brisbane, 4000, QLD, Australia.

*Corresponding author: ozgur.dedehayir@qut.edu.au

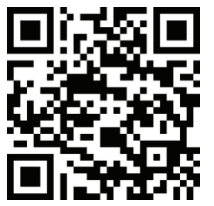


In fact, a number of large organizations are already building solutions that deploy IoT. Together with its ecosystem partners, Intel has defined a system architecture specification (SAS) to connect almost any type of device to the cloud, whether it has native internet connectivity or not. In a similar vein, the IBM Watson technology platform extends the power of cognitive computing to the Internet of Things, while Microsoft's Azure IoT platform helps to connect devices, analyze previously-untapped data, and integrate business systems. The Google Brillo project meanwhile introduces an Android-based embedded OS that brings the simplicity and speed of mobile software development to IoT hardware, thus making it cost-effective to build a secure, smart device, and to keep it updated over time.

Within the scope of this paper and commensurate with the definition provided by recent scholars (Gawer \& Cusumano, 2013; Gawer \& Henderson, 2007; Gawer \& Phillips, 2013), we refer to such IoT systems as industry platforms. Rather than focusing on the strategies of businesses such as Netflix, Airbnb, Spotify, and online 3D printing service providers (Rayna et al. 2015), however, the primary line of inquiry driving this research pertains to how these disruptive business models are facilitated by industry platforms, specifically in the IoT context. Through this study we aim to contribute to the platform and business ecosystem literatures, with our findings anticipated to carry relevance not only for the facilitation of IoT disruptive innovations, but also for disruption in other contexts employing industry platforms.

\section{Theoretical Background}

In the research domain of business economics, the evolution of platform thinking can be traced back to the 1990s when the concept 'product platform' was first introduced. Product platforms describe how companies achieve cost savings and benefit from adopting an in-house modular architecture for their product development process (Cusumano, 2010). As a result, the role of a product platform has traditionally been to serve as a foundation around which a company can develop a series of related products by reusing common components. Over time, observing the evolution of technology and rise of the Internet, scholars have proposed the concept of 'industry platform' (Gawer \& Cusumano, 2002). Similar to an in-house product platform, an industry platform offers a common base (often technological) that an organization can reuse in different product variations (Cusumano, 2010). However, the parts of an industry platform are not exclusively provided by a single organization nor is the usage kept in-house. Instead, due to increased scale and impact, the technological components of industry platforms are likely to be added by different external, autonomous agents referred to as complementors (Gawer \& Cusumano, 2013).

Recent research streams have added more dimensions to our understanding of industry platforms by considering two different approach angles. Firstly, the economic perspective, focused on platform competition, views platforms as multi-sided markets (Hagiu \& Wright, 2015; Hagiu, 2006). This perspective allows the evaluation of network effects, which explain strategic pricing behavior and product design decisions in two-sided markets (Parker \& Van Alstyne 2005; 2012), as well as the identification of challenges and working strategies for multisided platforms (Eisenmann et al., 2006; Hagiu, 2014; Muzellec et al., 2012). Secondly, the engineering design perspective, concerned with platform innovation, views platforms as technological architectures (e.g. Chesbrough, 2003). This research stream established that platforms systems evolve due to a combination of stability and variety made possible by their interfaces (e.g. Baldwin \& Woodard, 2008). With the need for a more holistic view on technological platforms, the two theoretical perspectives have been recently integrated into one comprehensive framework that refers to platforms as evolving organizations, and distinguishes between three main categories: internal platforms, supply chain platforms, and industry platforms (Gawer, 2014). This integrative framework states that internal platforms are used exclusively within one firm and governed by internal managerial authority, while a supply chain platform is shared by partners within a supply chain organizational structure having the coordination mechanisms enforced by contractual relationships. According to the same framework, industry platforms are seen as operating at the ecosystem level, and having specific ecosystem governance mechanisms. The latter offers potentially unlimited external innovative capabilities, allowing a myriad of external agents (e.g. complementors) to innovate without restrictions (Gawer, 2014).

\section{Research Method}

We studied the industry platform's facilitation of disruptive business models through a multiple case study design (Eisenhardt, 1989; Yin, 1994). Our design selection was motivated primarily by the very little that is known about the phenomenon in question and the relative nascence of conceptual frameworks built to study platforms, which guided us towards an exploratory, inductive method (Edmondson \& Mcmanus, 2007). The multiple cases allowed us to implement a replication logic (Yin, 1994), through which we could seek repeating patterns among the cases that informed of an underlying theory. Our study focused on four industry platform firms that allowed IoT businesses to build their offerings upon, drawn from a population predefined with respect to two major considerations. The selected population comprises firms that firstly operate according to a platform-based business model, and secondly relate to businesses in one of the identified IoT related areas - including networks for IoT, sensors for collecting data, and infrastructure for assuring the data flow, processing, and analysis (Atzori et al., 2010). We implemented theoretical sampling to select the cases for our investigation, using additional theoretical criteria provided by the literature in defining the concept of industry platforms (Gawer, 2014). According to Gawer (2014), industry platforms share a set of characteristics which set them apart from other types of platforms, such as internal platforms (i.e. a platform that operates within firms, allowing connectivity between sub-units through a closed technological interface) and supply chain platforms (i.e. a platform that operates across supply chains, enabling suppliers to deliver components to an assembler, with a semi-closed technological interface). As this paper focuses exclusively on industry platforms (i.e. platforms that operate 
across industry ecosystems, with an open technological interface), we have selected the case firms as real world representations of this theoretical notion. Table 1 offers a description of each of the four selected companies ${ }^{1}$.

Table 1: Overview of the four industry platform companies studied.

\begin{tabular}{l|l|l|l}
\hline Company & Description & Size & Year founded \\
\hline Company A & $\begin{array}{l}\text { Industry platform for capturing, processing, visualizing and controlling enormous } \\
\text { amounts of IoT data in real-time. }\end{array}$ & $\begin{array}{l}51-200 \\
\text { employees }\end{array}$ & 2001 \\
\hline Company B & IoT platform for connecting devices with proximity awareness to the cloud. & $\begin{array}{l}51-200 \\
\text { employees }\end{array}$ & 2013 \\
\hline Company C & Cloud-based data analytics platform for the IoT. & $\begin{array}{l}1-10 \\
\text { employees }\end{array}$ & 2011 \\
\hline Company D & $\begin{array}{l}\text { A business unit of a large multinational set up to develop solutions within the IoT } \\
\text { context. }\end{array}$ & $\begin{array}{l}10,001+ \\
\text { employees* }\end{array}$ & $2014^{* *}$ \\
\hline
\end{tabular}

* This is the total number of employees of the organization and not of the IoT dedicated business group.

** This is the year the IoT focused business group was founded within the organization.

Company A's platform provides new ways for IoT firms to capture, process, visualize and control enormous amounts of data in realtime, which can help businesses in various industries improve what they do, and how they do it. The service is a next generation SaaS (Software as a Service) suite that enables customers to gather system, network and cloud measurement data, and arrange the information in a context that is relevant to businesses and their customers. The offered service displays the data in an easily understandable, concise and relevant way, in real-time as well as historically. A unified view of status and performance can be seen at a glance, not limited only to infrastructure but also to applications and services.

Company B's platform helps IoT firms build technological proximity solutions using beacons. These are fundamentally very simple pieces of hardware - small, generally very short ranged, battery-powered devices that broadcast a unique signal at regular intervals over Bluetooth radio. Because Bluetooth is very short ranged it rarely detects a signal beyond 30-40 meters, however, this is not a flaw but rather a feature. When the signal is detected it means that a person or an object (carrying a beacon reader device) is in proximity of a stationary beacon, and a series of such detections can further identify when the person or object is in motion. While this system may seem similar to GPS, the latter provides physical location data and requires a lot of battery power to operate.

Company $\mathrm{C}$ provides a cloud-based data analytics platform for IoT firms, offering real-time decision making capabilities to users and devices. It has been built with big data tools to manage large amounts of devices and data streams with very high frequency sample rates. The platform has also been designed to allow IoT entrepreneurs and developers to start with small test projects and scale up to capture millions of streams of data coming in from sensors, apps, and other fixed and mobile devices across the globe. The firm has patented its data analytics platform component which gives immediate access to stream data, roll-up data, and up to 140 statistics per stream. It is designed as a horizontal platform to be used across all industries.

Finally, Company D's digital platform represents a new era in connected healthcare for both patients and providers, as healthcare continues to move outside hospital walls, and into patients' homes and everyday lives. The platform, supported by salesforce.com, is open and cloud-based, which collects, compiles and analyzes clinical and other data from multiple devices and sources to be used by IoT firms. Health systems, care providers and individuals can access data on personal health, specific patient conditions and entire populations so care can be more personalized and people empowered in their own health, wellbeing and lifestyle.

\subsection{Research instruments and protocols}

We employed semi structured-interviews as the predominant tool for data gathering, supplemented by secondary sources such as corporate websites. The interviews comprised two sections: (i) to gain insights about the firms' industry platforms, and (ii) to gain the respondents' opinions on the platform's facilitation of disruptive innovation. Special attention was given to collect an even and balanced amount of data regarding both themes from each interview. Questions were firstly asked about industry platforms, and were followed by questions about disruptive innovation. For the second interview component, we were well aware of the ongoing debate in the literature on the definition of disruptive innovation. Despite the concept's introduction more than 20 years ago, opinions remain divided as to how disruptive innovations can be observed in the real world, as reflected in a recent

${ }^{1}$ The firms selected for our study chose to remain unidentified. Any sensitive information was therefore left out and the study was conducted by assuring the complete anonymity of the participants. Nevertheless, the research process and the results acquired from the study were not affected. 
article entitled "What Is Disruptive Innovation?" appearing in the Harvard Business Review (Christensen et al., 2015). As a result, the risk in our data collection process was the interviewees' lack of clarity of the concept (e.g. seen to be synonymous with radical innovation), as defined by Christensen and his colleagues and the definition we employ in our research. A special strategy was thus adopted to mitigate this risk, whereby, rather than asking the respondents' perception of disruption directly, the interview questions were devised to reflect the characteristics of disruptive innovation, thus acquiring insights on this issue indirectly.

Due to the strategic nature of the concepts analyzed in our research we interviewed the highest level of management in each of the case firms (see Table 2). The duration of interviews ranged from one hour to one hour and twenty minutes.

Table 2: Respondents and the timetable for data collection.

\begin{tabular}{l|l|l}
\hline Firm & $\begin{array}{l}\text { Interviewees level in } \\
\text { the company }\end{array}$ & Date of collection \\
\hline Company A & C-level & November 2015 \\
\hline Company B & Senior management & December 2015 \\
\hline Company C & VP level & December 2015 \\
\hline Company D & Senior management & $\begin{array}{l}\text { December 2015 - January } \\
2016\end{array}$ \\
\hline
\end{tabular}

\subsection{Data analysis}

The process of analyzing data and reaching conclusions from case study research is a highly systematic one. The process involves constant iteration backward and forward between data analysis, shaping hypotheses, and enfolding literature, and reaching closure when marginal improvements become insignificant (Eisenhardt, 1989). It starts with the step of analyzing data, which is seen as the heart of building theory from case studies, but is, at the same time, the most difficult and least transparent component. The difficulty often lies in the coding and interpreting the transcripts once the interviews have been completed (Burnard, 1991). We took special care to deal with this challenge.

Each interview from our four case studies was recorded in full, transcribed in full, and coded using a generic form of open-coding meaning that the categories were freely generated. The interview transcriptions were analyzed using a method of thematic content analysis, a method that is particularly suitable for semi-structured interviews (Burnard, 1991). The aim of this exercise is to produce a detailed and systematic recording of the themes and issues addressed in the interviews and to link the themes and interviews together under a reasonably comprehensive category system. For validation purposes multiple researchers evaluated the coding, and emerging discrepancies were then discussed to reach consensus.

A thorough reading of the transcripts allowed us to become immersed in the data. This process of immersion was used to increase our awareness of the "outside world" of the respondent and to enter the other person's "frame of reference" (Burnard, 1991). As many codes as necessary were generated to label all aspects of the content of each interview. The issues that were not related to the themes of interest, namely, 'platform thinking' and 'disruptive innovation', were intentionally left out. The categories were freely generated at this stage. As certain categories occurred more than once, the emerging coding labels were ranked based on the frequency of their appearance, such that codes appearing multiple times were considered to be recurring themes, as shown in Fig. 1.

Fig. 1: The five most commonly occurring categories for each case.

\section{Company $\mathrm{A}$}

\#amazon_customers_building_their_own_platforms

\#amazon_loT_is_expensive

\#paradigm_change

\#fault_tolerance_platform

\#modular_structure_platform

\section{Company C}

\#serve_side_A

\#platform_simple_and_easy_to_use

\#data_analytics

\#side_A_can_build_solutions_for_any_industry

\#software_interface_is_important

\section{Company B}

\#proximity_relevant_for_many_industries

\#serve_side_A

\#proximity_technology_is_disruptive

\#adding_value_beyond_hardware

\#proximity_platform

\section{Company D}

\#analytics

\#focus_on_healthcare_market

\#preventive_medicine

\#serve_side_B_directly

\#lot_platform_for_healthcare 
The emergent list of categories was, in turn, grouped together under higher-order concepts (i.e. in order to reduce the numbers of categories, similar labels were grouped into broader themes). Following a repetitive process, a new category catalogue was developed and overlapping headings removed to refine and produce a final list. Interview transcripts were read through one more time in light of the final list of categories, to establish the degree with which they covered all aspects of the interviews. Adjustments were made as necessary in line with the stage-by-stage method of analyzing qualitative interview data (Burnard, 1991). The final list of broader themes (containing grouped categories) for each case is provided in Table 3.

Table 3: Final list of broader themes for each case.

\begin{tabular}{|c|c|c|c|}
\hline $\begin{array}{l}\text { modular structure } \\
\text { open platform } \\
\text { fault tolerant platform } \\
\text { linear scalability } \\
\text { service level agreement } \\
\text { multitenancy platform } \\
\text { shift from fire-and-forget } \\
\text { no external dependencies } \\
\text { serve verticals directly } \\
\text { continuously feeding data } \\
\text { serve different industries } \\
\text { fast deployment platform } \\
\text { data repository platform } \\
\text { data retrieval platform } \\
\text { data visualization platform } \\
\text { disruption as a service } \\
\text { platform complementors }\end{array}$ & $\begin{array}{l}\text { proximity technology } \\
\text { serve verticals directly } \\
\text { proximity platform } \\
\text { analytics } \\
\text { hardware platform } \\
\text { software platform } \\
\text { open platform } \\
\text { platform complementors } \\
\text { available across industries } \\
\text { proximity technology broadly appli- } \\
\text { cable }\end{array}$ & $\begin{array}{l}\text { advanced backend } \\
\text { customers pull solutions } \\
\text { analytics } \\
\text { fast deployment } \\
\text { platform security } \\
\text { simplicity } \\
\text { easy to use } \\
\text { serve different industries } \\
\text { platform complementors } \\
\text { software platform } \\
\text { open platform } \\
\text { real time visualization } \\
\text { scalability } \\
\text { serve verticals directly } \\
\text { stay horizontal } \\
\text { user experience is critical }\end{array}$ & $\begin{array}{l}\text { analytics } \\
\text { focus on healthcare } \\
\text { fast deployment } \\
\text { platform for healthcare } \\
\text { multitenancy platform } \\
\text { open platform } \\
\text { hardware agnostic } \\
\text { preventive medicine } \\
\text { serve verticals directly } \\
\text { special regulations } \\
\text { agile } \\
\text { generic capabilities } \\
\text { real time flexible } \\
\text { complementors } \\
\text { platform reliability } \\
\text { artificial intelligence } \\
\text { modular structure } \\
\text { platform security } \\
\text { multi layered platform } \\
\text { evolved from internal platform } \\
\text { part of a bigger organization }\end{array}$ \\
\hline
\end{tabular}

Following the completion of the interview coding process, we undertook the highly iterative process of systematically comparing the emergent theoretical constructs from cases with existing literature. The main aim of this exercise is to compare theory and data, iterating towards generating theory which is tightly linked to the data. Linking results to the literature is particularly important in theory building research from case studies because the findings rely on a limited number of cases (Eisenhardt, 1989).

We continued by analyzing within-case data in order to become intimately familiar with each case individually as a stand-alone entity. This step allowed the emergence of unique patterns from each case before cross-case patterns were developed. Next, the within-case analysis was coupled with cross-case analysis in search of patterns in the data. To negotiate the danger of reaching premature and even false conclusions as a result of information-processing biases, we looked at the data in divergent ways. To this end, we employed the tactic of selecting categories or dimensions, and then looking for withingroup similarities coupled with intergroup differences.

\section{Dimensions that Define Industry Platforms for IoT}

We observe that the industry platforms of Company A and Company $\mathrm{C}$ are designed to allow IoT firms to develop products and services upon these platforms, without major restrictions on the technology used or the industry served. By contrast, Company B's industry platform is built around one particular technology, namely, the proximity technology. Despite its technological restriction, the platform allows IoT firms to leverage this technological capability to develop solutions that can serve multiple industries. As for Company D, while it does not impose any technological restriction, its industry platform appears to constrain IoT firms in building solutions for only a single industry (the platform has a clear focus on healthcare and will only accept solutions that serve the healthcare market).

Two dimensions subsequently emerged from these observations, which help define and classify industry platforms for the Internet of Things context: 


\section{(1) Technological focus}

This dimension captures the scope of technologies that can be utilized by IoT firms in building their solutions upon a given industry platform. With respect to this dimension, industry platforms range from specific to generic technologies that they sponsor. For instance, Company B's platform enables solutions using only proximity technology (a specific technological focus), whereas Company D does not impose any constraint on technologies used to develop solutions (a generic technological focus).

\section{(2) Industry focus}

This dimension captures the scope of industries that can be accessed by IoT firms, which build their solutions upon a given platform. With respect to this dimension, industry platforms range from a few to many industries that they support (or restrict) solutions for. For example, Company D has a clear focus on healthcare, and will only accept solutions that serve the healthcare market (serves few industries), whereas Company B does not constrain the markets IoT firms would like to provide solutions for (serves many industries).

Used in conjunction, these two dimensions have led us to propose the framework (a taxonomy of industry platforms) depicted in Fig. 2.

Fig. 2: Taxonomy of industry platforms facilitating IoT businesses.

\begin{tabular}{|c|c|c|}
\hline \multirow{2}{*}{$\begin{array}{l}\text { Industries } \\
\text { served by } \\
\text { platform }\end{array}$} & $\begin{array}{l}\text { I. Technology-Centric } \\
\text { No industry focus } \\
\text { Technology focus }\end{array}$ & $\begin{array}{l}\text { II. Generalist } \\
\text { No industry focus } \\
\text { No technology focus }\end{array}$ \\
\hline & $\begin{array}{l}\text { IV. Specialist } \\
\text { Industry focus } \\
\text { Technology focus }\end{array}$ & $\begin{array}{l}\text { III. Industry-Centric } \\
\text { Industry focus } \\
\text { No technology focus }\end{array}$ \\
\hline Few & $\begin{array}{l}\text { Techno } \\
\text { sponso }\end{array}$ & $\begin{array}{l}\text { I solutions } \\
\text { platform }\end{array}$ \\
\hline
\end{tabular}

This framework delineates industry platforms with respect to the breadth of activities they sponsor, or their 'niche width'. According to population ecology theory (Hannan \& Freeman, 1977; Loree, 2008), niche width refers to "a population's tolerance for changing levels of resources, its ability to resist competitors, and its response to other factors that inhibit growth" (Freeman \& Hannan, 1983). Organizational populations that have a broad niche width are said to be 'generalists', while those with a narrow niche width referred to as 'specialists'. An organization's niche width may be measured with respect to different dimensions. In our framework we employ the industry focus and technology focus dimensions to determine the niche widths of the four companies, with broad niche width (generalist) platforms located in Quadrant II, and narrow niche width (specialist) platforms in Quadrant IV. Quadrants I and III mark specialism with respect to a particular dimension while generalism with respect to the other.

Technology-centric industry platforms offer a specific technology to external innovators (i.e. IoT firms), which can be employed to create solutions to serve many industries. According to this definition, we position Company B in Quadrant I. By contrast, industry-centric platforms offer a generic technology for external innovators to develop solutions to serve only a few industries, subsequently positioning Company D in Quadrant III. Quadrant II comprises generalist platforms offering a generic technology that can be employed to create solutions to serve many industries. This quadrant subsequently comprises Company A as well as Company C. Finally, specialist industry platforms allow IoT businesses to utilize a specific technology to serve only a few industries. None of the case firms displayed these characteristics, leaving Quadrant IV unoccupied within the scope of our exploration.

The vacancy of Quadrant IV can be explained by extrapolating the works of population ecology scholars that suggest the generalist strategy to be fitting for uncertain environments in ensuring the survival firms. In other words, specialism can be a risky tactic when the environment is uncertain, with the organization focusing on a limited bandwidth of resources. In the relatively nascent (and therefore uncertain) context of industry platforms for the Internet of Things, we anticipate that a generalist strategy is therefore more likely to be deployed in preference to a specialist one - hence the current vacancy of Quadrant IV. Notwithstanding, we expect specialist industry platforms to successfully enter the fray as the IoT context matures over time.

Our proposed framework complements the existing literature on platforms by underscoring the fundamental decisions platform leaders undertake in establishing their ecosystems, and designing industry architectures that determine the ways in which activities along the value chain are divided between industry participants (Hatchuel et al., 2010; Parker \& Van Alstyne, 2012; Tee \& Gawer, 2009; Thomas et al., 2014). In this regard, we suggest that the four 'levers' of successful platform leadership - scope (the activities to be performed by the platform leader as opposed to those performed by external parties), technology design (functionalities included in the platform, degree of modularity, and openness to outside firms), external relationships (managing complementors), and internal organization (assuring external collaborators of ecosystem viability through the platform leader's internal processes) - can be deployed with varying strength in different quadrants of the framework. For instance, the scope lever may be manipulated by the technology-centric industry platform leader to ensure greater control of technological activities undertaken in its ecosystem that serves multiple industries, while the industry-centric platform leader may focus on the technology design lever to create higher degree of openness for external parties to serve an industry with a multitude of technological solutions. 


\section{Facilitation of Disruptive IoT Innovation}

Since the development of the disruptive innovation theory (Christensen \& Bower, 1995; Christensen \& Rosenbloom, 1995; Christensen, 1997 ) its popularity among researchers has increased steadily while its enhancement and refinement has also grown considerably (Markides 2006). Christensen distinguishes disruptive innovations based on the market where they impact as low-end market disruptions and new market disruptions. Scholars have since differentiated disruptive innovation types based on their diverse competitive effects and the markets they create (Charitou \& Markides, 2003; Gilbert \& Bower,
2002; Markides, 2006; Dedehayir et al., 2014). From the work of prior scholars, we synthesize three generic forms of disruptive innovation: (i) disruption with business model innovation; (ii) disruption with product (new-to-the world) innovation; and (iii) disruption with technological innovation. For the purposes of this exploratory study, however, we have grouped the product and technological modes of disruptive innovation into a single category (technological disruptive innovation), given their commonality as innovations that are customer-centric, as distinct from business model disruptive innovations that are firm-centric. We provide an overview of these two overarching modes of disruption in Table 4.

Table 4: Overview of disruption with business model innovation and technological innovation.

\begin{tabular}{|c|c|c|}
\hline & Business model disruptive innovation & Technological disruptive innovation \\
\hline Definition & $\begin{array}{l}\text { Discovery of a fundamentally different business model in an } \\
\text { existing business. }\end{array}$ & $\begin{array}{l}\text { Innovations the disruptive tendencies of which stem from advancements } \\
\text { in technological components, resulting in new-to-the-world products or } \\
\text { services. }\end{array}$ \\
\hline Aspects & $\begin{array}{l}\text { Extends the "economic pie" by attracting new customers, and } \\
\text { expands the existing market by convincing existing customers } \\
\text { to consume more. } \\
\text { Does not imply launch of a new product or service, but the re- } \\
\text { definition of what a product or service is and how it is provided } \\
\text { to the customer. } \\
\text { Requires a different and conflicting value chain from the ones } \\
\text { of incumbents. }\end{array}$ & $\begin{array}{l}\text { Perturbs prevailing consumer habits and behaviors in a major way. } \\
\text { Results from supply-push processes rather than demand-pull approaches. } \\
\text { Early pioneers are very rarely the ones that capture the market, while late- } \\
\text { comers' products are generally preferred by the average consumer. } \\
\text { The new technology changes the traditional attributes with respect to } \\
\text { which firms compete. } \\
\text { The new technology makes the product cheaper and broadly available. }\end{array}$ \\
\hline Impact & $\begin{array}{l}\text { It is difficult for incumbents to make the new and established } \\
\text { business models coexist. }\end{array}$ & $\begin{array}{l}\text { The new technology undermines the competencies and complementary } \\
\text { assets upon which incumbents have built their success. }\end{array}$ \\
\hline Strategies & $\begin{array}{l}\text { Incumbents may invest in their existing business model to } \\
\text { compete more aggressively with the new business model. }\end{array}$ & $\begin{array}{l}\text { Incumbents should create small or start-up firms that are autonomous in } \\
\text { governance. }\end{array}$ \\
\hline Examples & $\begin{array}{l}\text { No-frills airlines; internet banking and internet brokerage; } \\
\text { internet bookstores }\end{array}$ & $\begin{array}{l}\text { The automobile; televisions; PCs; mobile phones; hard disk drives; digital } \\
\text { cameras; minicomputers. }\end{array}$ \\
\hline
\end{tabular}

* Table adapted from existing literature (Charitou \& Markides 2003; Danneels 2004; Gilbert \& Bower 2002; Markides 2006; Dedehayir et al. 2014).

To uncover how industry platforms facilitate disruptive IoT innovations we map the two modes of disruption defined in Table 4, onto the taxonomy of industry platforms presented in Fig. 2. If the industry platform allows a specific technology to be used by IoT businesses, it implies that these external innovators are likely to have less control of the technology and need to innovate with their business models to disrupt the market. This necessity is further exacerbated by, for instance, the dictation of complementary hardware, in addition to the software, which the industry platform makes available for IoT firms (as witnessed for Company B), in a sense, locking the latter onto a specific technological path. When, by contrast, the industry platform limits the application context (i.e. the industries) for IoT firms, but with no technological restrictions, these external innovators should have greater propensity to disrupt the market with technological innovations, such as through the low-end disruption mechanism. The outcomes of this mapping process are shown in Fig. 3. 
Fig. 3: Modes of disruptive IoT innovation facilitated by different types of industry platforms.

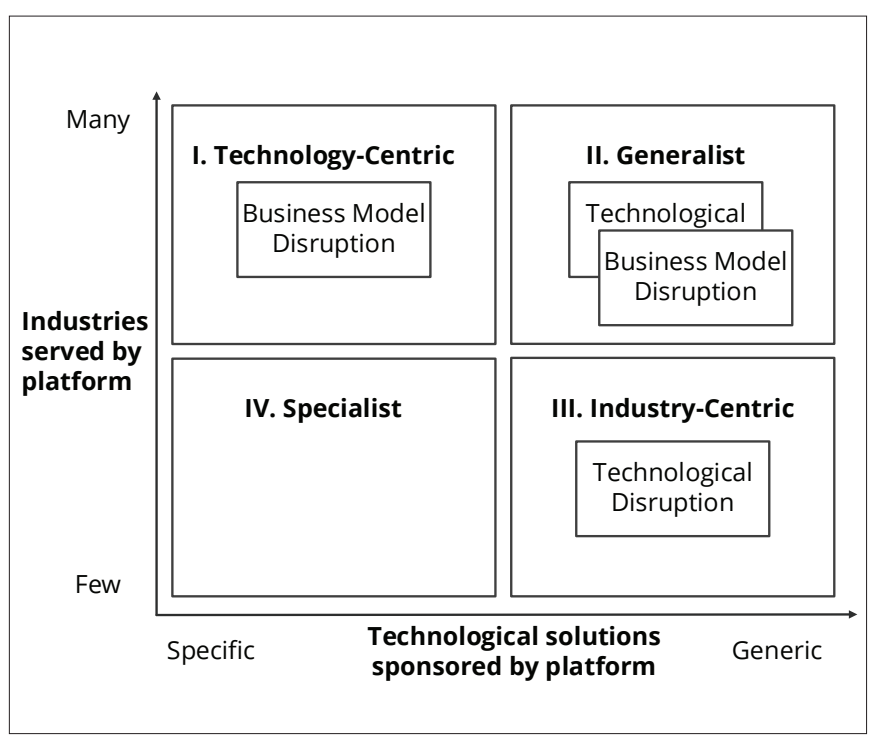

We synthesize the outcomes of this mapping exercise through the following three propositions:

Proposition 1: Technology-centric industry platforms that have a specific technological focus, but allow the serving of many industries, are more likely to facilitate business model disruptive IoT innovations.

Proposition 2: Industry-centric industry platforms that have a generic technological focus, but allow the serving of only a few industries, are more likely to facilitate technological disruptive IoT innovations.

Proposition 3: Generalist industry platforms that have a generic technological focus and serve many industries are likely to facilitate business model and technological disruptive IoT innovations.

Our propositions complement existing research that welds business model innovation and platform design, addressing issues such as designing a winning business model through platform thinking (Cennamo \& Santalo, 2015; Chen et al., 2009; Frery et al., 2015; Markus \& Loebbecke, 2013). From the industry platform perspective, a generic platform design invites a greater number of IoT firms, which may themselves vary with respect to the scope of industrial and technological application of their offerings. On the contrary, a specialist platform strategy will limit the number of IoT firms to only those that develop offerings in restricted industrial and technological applications, precluding IoT firms that desire to develop offerings for a wider audience. The degree of generalism-specialism is therefore a strategic design choice of industry platform firms, which can determine their success bestowed by the population of complementary firms that build upon the platforms. On this point we may emphasize one of the platform traps identified by Cennamo and Santalo (2015), namely that, attempting to conquer the mainstream market while concurrently attempting to win a niche market segment is a highly difficult task. It may therefore follow that technology-centric and industry-centric platform strategies are likely to be less successful than the generalist or specialist designs in fostering disruptions.

\section{Conclusions}

While much of the attention among academics and practitioners has hitherto centered on disruptors, and the incumbents that suffer the consequences of disruption, our aim in this paper has been to move beyond the disruptor-incumbent dichotomy, and to capture the important backstage role assumed by companies like Amazon, in facilitating disruptive change through their platform designs. More specifically, this paper aimed to unveil insights about facilitating the emergence of disruptive IoT (Internet of Things) firms, inspired by the successes of companies such as Netflix, Airbnb, and Spotify that have fundamentally changed the way their respective markets are served. We focused on industry platforms upon which IoT firms can build their disruptive products and services, in the same manner Netflix, Airbnb, and Spotify have established their businesses upon Amazon's Amazon Web Services platform.

Given the very nascence of the topic under consideration, we have implemented an inductive research design, with the objective of building theory from case studies in the IoT realm. Our exploration of four firms providing industry platforms for IoT applications led us to propose a taxonomy of industry platforms based on their degree of specialism along two dimensions - industry focus (number of industries that can be served), and technology focus (scope of technological solutions allowed). This taxonomy includes our industry platform types: (i) the generalist (many industries and wide scope of technological solutions); (ii) the technology-centric (many industries but narrow scope of technological solutions); (iii) the industry-centric (a few industries but wide scope of technological solutions); and (iv) the specialist (a few industries and narrow scope of technological solutions).

In turn, by conceptually mapping two generic types of disruptive innovation identified from our examination of the literature upon this taxonomy, we proposed that technology-centric industry platforms are more likely to facilitate business model disruptions, while industry-centric platforms are more likely facilitate technological disruptions. Generalist industry platforms, by contrast, are able to facilitate both business model and technological disruptions, given the freedom they allow IoT firms to build their product and service solutions.

The paper contributes to the industry platform and business ecosystem literatures by underlining the role industry platforms enact in facilitating the emergence of new businesses. Our work firstly has implications for industry platform companies, whose success is reliant on IoT firms' ability to innovate upon their platforms. The proposed framework can assist industry platforms companies strategically position themselves with respect to the dimensions of industry and technology focus, thereby attracting IoT firms with a particular disruptive innovation vision. Our work is secondly relevant for IoT 
firms that aim to disrupt the market with new product or service solutions. Specifically, the proposed model can aid these firms select the industry platform that will best facilitate the mode of disruption (i.e. business model or technological) that they have internal capabilities to execute.

There are limitations of this study that need mention however. Firstly, our results are constrained by the exploratory nature of our work and by the number of cases considered. Although the four cases selected in this paper allowed us to propose a theoretical framework from their analyses, we believe that the examination of a larger number of cases in future work would validate and strengthen our propositions. A second limitation is born from the theoretical sampling implemented in selecting cases. While this method helped us focus in on the highly interesting empirical setting of the Internet of Things, the relevance of our results to other settings needs to be concluded with some care. Nevertheless, the scope of industries as well as the geographical diversity covered in the cases provides some confidence of the transferability of our findings to different industry and platform contexts.

Our study opens stimulating possibilities for future work. A natural continuation of this study is the employment of the proposed industry platform taxonomy in different empirical examinations and the testing of our propositions. Another fruitful research agenda will be to establish the conditions under which an industry platform should pursue an industry-centric or technology-centric strategy, and the conditions that warrant generalist or specialist tactics. Furthermore, given the evolutionary nature of industry platforms, the analysis of these platforms' movement within our emergent framework can provide valuable insights with respect to success factors. Finally, our proposed framework can be extended through future work that takes into account the strategic thinking of external innovators (i.e. IoT firms), which aim to develop disruptive innovations.

\section{References}

Ansari, S., \& Krop, P. (2012). Incumbent performance in the face of a radical innovation: Towards a framework for incumbent challenger dynamics. Research Policy, 41(8),1357-1374.

Atzori, L., Iera, A., \& Morabito, G. (2010). The Internet of Things: A survey. Computer Networks, 54(15), 2787-2805.

Baldwin, C.Y., \& Woodard, C.J. (2008). The architecture of platforms: A unified view. Working Papers -- Harvard Business School Division of Research, 1-31.

Bouverot, A. (2015). GSMA: The impact of the Internet of Things. The connected home, 20.

Brown, J., Hendry, C., \& Harborne, P. (2007). Developing radical technology for sustainable energy markets: The role of new small firms. International Small Business Journal, 25(6), 603-629.

Burnard, P. (1991). A method of analysing interview transcripts in qualitative research. Nurse Education Today, 11(6), 461-466.
Cennamo, C., \& Santalo, J. (2015). How to avoid platform traps. MIT Sloan Management Review, 57(1), 12-15.

Charitou, C.D., \& Markides, C.C. (2003). Responses to disruptive strategic innovation. MIT Sloan Management Review, 44(2), 55-63.

Chen, J., Zhang, C., \& Xu, Y. (2009). The role of mutual trust in building members' loyalty to a $\mathrm{C} 2 \mathrm{C}$ platform provider. International Journal of Electronic Commerce, 14(1), 147-171.

Chesbrough, H. (2003). Open platform innovation: Creating value from internal and external innovation. Intel Technology Journal, $7(3), 7$.

Christensen, C.M. (1997). The Innovator's Dilemma: When New Technologies Cause Great Firms to Fail. Boston: MA: Harvard Business School Press.

Christensen, C.M., \& Bower, J.L. (1995). Customer power, strategic investment, and the failure of leading firms. Strategic Management Journal, 17, 197-218.

Christensen, C.M., \& Rosenbloom, R.S. (1995). Explaining the attacker's advantage: Technological paradigms, organizational dynamics, and the value network. Research Policy, 24(2), 233-257.

Cusumano, M. (2010). Technology strategy and management: The evolution of platform thinking. Communications of the ACM, 53(1), 32.

Danneels, E. (2004). Disruptive technology reconsidered: A critique and research agenda. Journal of Product Innovation Management, 21(4), 246-258.

Dedehayir, O., Nokelainen, T., \& Makinen, S.J. (2014). Disruptive innovations in complex product systems industries: A case study. Journal of Engineering and Technology Management, 33, 174-192.

Ebersold, K., \& Hartford, T. (2015). The impact of disruptive technology: The Internet of Things. Issues in Information Systems, 16(4), 194-201.

Edmondson, A.C., \& Mcmanus, S.E. (2007). Fit in methodological management. Academy of Management Review, 32(4), 1155-1179.

Eisenhardt, K.M. (1989). Building theories from case study research. Academy of Management Review, 14(4), 532-550.

Eisenmann, T., Parker, G., \& Alstyne, M.W. Van. (2006). Strategies for two- sided markets. Harvard Business Review, 84(10), 12.

Fleisch, E. (2010). What is the Internet of Things? An economic perspective. Economics, Management, and Financial Markets, 5(2), $125-157$.

Freeman, J., \& Hannan, M.T. (1983). Niche width and the dynamics of organizational populations. American Journal of Sociology, 88(6), 1116-1145. 
Frery, F., Lecocq, X., \& Warnier, V. (2015). Competing with ordinary resources. MIT Sloan Management Review, Spring, 1-14.

Gawer, A. (2014). Bridging differing perspectives on technological platforms: Toward an integrative framework. Research Policy, 43(7), 1239-1249.

Gawer, A., \& Cusumano, M.A. (2013). Industry platforms and ecosystem innovation. Journal of Product Innovation Management, 31(3), 417-433.

Gawer, A., \& Cusumano, M.A. (2002). Platform Leadership: How Intel, Microsoft, and Cisco Drive Industry Innovation, Harvard Business School Press: Boston.

Gawer, A., \& Henderson, R. (2007). Platform owner entry and innovation in complementary markets: Evidence from Intel. Journal of Economics and Management Strategy, 16(1), 1-34.

Gawer, A., \& Phillips, N. (2013). Institutional work as logics shift: The case of Intel's transformation to platform leader. Organization Studies, 34(8), 1035-1071.

Gilbert, C., \& Bower, J.L. (2002). Disruptive change. Harvard Business Review, 80(5), 94-101.

Gubbi, J., Buyya, R., Marusic, S., \& Palaniswami, M. (2013). Internet of Things (IoT): A vision, architectural elements, and future directions. Future Generation Computer Systems, 29(7), 1-19.

Hagiu, A. (2014). Strategic decisions for multisided platforms. MIT Sloan Management Review, 55(2), 71-80.

Hagiu, A. (2006). Multi-Sided platforms: From microfoundations to design and expansion strategies. Business, 1-25.

Hagiu, A., \& Wright, J. (2015). Multi-sided platforms. International Journal of Industrial Organization, 43, 162-174.

Hagiu, A., \& Wright, J. (2013). Structuring your business as a marketplace may seem attractive, but it's often a recipe for failure. Harvard Business Review, 103-108.

Hannan, M.T., \& Freeman, J. (1977). The population ecology of organizations. American Journal of Sociology, 82(5), 929-964.

Harris, I., Wang, Y., \& Wang, H. (2015). ICT in multimodal transport and technological trends: Unleashing potential for the future. International Journal of Production Economics, 159, 88-103.

Hoelck, K., \& Ballon, P. (2015). Competitive dynamics in the ICT sector Strategic decisions in platform ecosystems. Communications \& Strategies, 21.

Kenagy, J.W., \& Christensen, C.M. (2002). Disruptive innovation: A new diagnosis for health care's "financial flu". Healthcare financial management, 56(5), 62-66.
Loree, D. (2008). Density-dependent strategic action: Outcomes of structural market commitment in the global integrated circuit industry. Journal of Engineering and Technology Management, 25(1-2), 23-57.

Markides, C. (2006). Disruptive innovation: In need of better theory. The Journal of Product Innovation Management, 23(1), 19-25.

Markus, M.L., \& Loebbecke, C. (2013). Commoditized digital processes and business community platforms: New opportunities and challenges for digital business strategies. MIS Quarterly, 37(2), 649-654.

Mikusz, M., Jud, C., \& Schäfer, T. (2015). Business model patterns for the connected car and the example of data orchestrator. Icsob, 114(April), 261-266.

Muzellec, L., Ronteau, S., \& Lambkin, M. (2012). Two-sided Internet platforms: A business model lifecycle perspective. Industrial Marketing Management, 45, 139-150.

Parker, G.G., \& Van Alstyne, M.W. (2012). A digital postal platform: Definitions and a roadmap. MIT Sloan School of Management, January, 30.

Parker, G.G., \& Van Alstyne, M.W. (2005). Two-sided network effects: A theory of information product design. Management Science, 51(10), 1494-1504.

Rayna, T., Striukova, L., \& Darlington, J. (2015). Co-creation and user innovation: The role of online 3D printing platforms. Journal of Engineering and Technology Management, 37, 90-102.

Rodrigues, M.A.D.S., Chimenti, P., Nogueira, A.R.R., Hupsel, L.F., \& Repsold, A. (2014). From print to screen: Changes and challenges facing the Brazilian publishing industry. Revista de Administração, 49(3), 491-505.

Sapsed, J., Grantham, A., \& DeFillippi, R. (2007). A bridge over troubled waters: Bridging organisations and entrepreneurial opportunities in emerging sectors. Research Policy, 36(9), 1314-1334.

Shea, C.M. (2005). Future management research directions in nanotechnology: A case study. Journal of Engineering and Technology Management, 22(3), 185-200.

Soleimani, F., \& Zenios, S. (2011). Disrupting incrementalism in health care innovation. Annals of surgery, 254(2), 203-208.

Tee, R., \& Gawer, A. (2009). Industry architecture as a determinant of successful platform strategies: A case study of the i-mode mobile Internet service. European Management Review, 6(4), 217-232.

Thomas, L.D.W., Autio, E., \& Gann, D.M. (2014). Architectural leverage: Putting platforms in context. Academy of Management Perspectives, 28(2), 198-219. 
Uckelmann, D., Harrison, M., \& Michahelles, F. (2011). Architecting the Internet of Things. Architecting the Internet of Things, January, $1-353$.

Walsh, S.T. (2004). Roadmapping a disruptive technology: A case study the emerging microsystems and top-down nanosystems industry. Technological Forecasting and Social Change, 71(1-2), 161-185.
Wang, Y., Kung, L.-A., \& Byrd, T.A. (2018). Big data analytics: Understanding its capabilities and potential benefits for healthcare organizations. Technological Forecasting and Social Change, $126,3-13$.

Yin, B.R.K. (1994). Case Study Research. Design and Methods. Sage Publications. p.312. 